\title{
Acute Fluoxetine Treatment Produce Anxiolytic Effects without Modulating Behaviour Response on Exposure to Forced Swimming Test
}

\author{
Shazia Dawood $^{1 *}$, Samina Bano ${ }^{2}$, Saira Bugti ${ }^{3}$ and Jai Kershan ${ }^{4}$ \\ ${ }^{1}$ Assistant Professor Department of Biochemistry, Federal Urdu University of Science, Arts and Technology Karachi, Pakistan \\ ${ }^{2}$ Professor Clinical Biochemistry and Psychopharmacology Research Unit Department of Biochemistry, University of Karachi, Pakistan \\ ${ }^{3}$ Professor Department of Pathology, Fazaiya Ruth Pfau Medical College PAF Faisal Base Karachi, Pakistan \\ ${ }^{4}$ Assistant Professor, Department of Community Health Sciences, United Medical and Dental College Korangi Creek Karachi, Pakistan
}

\begin{tabular}{ll}
\hline DOI:10.36348/SJMPS.2019.v05i09.008 & | Received: $16.07 .2019 \mid$ Accepted: $23.07 .2019 \mid$ Published: 21.09 .2019
\end{tabular}

*Corresponding author: Shazia Dawood

\section{Abstract}

Stress is a condition which disturbs physiological and psychological homeostasis mechanism. Depression is a severe psychiatric disorder. Biogenic amine theory of depression illustrate that the low level of brain 5 hydroxy tryptamine (5HT) and catecholamine leads to depressive symptoms. Immunological challenges can alter the tryptophan (TRP) metabolism, it is clinical indication of depression but stress also shift TRP metabolism. Fluoxetine is more effective anxiolytic drug as compared to others antidepressants. The aim of the current investigation is to examine the effects of fluoxetine administration on tryptophan metabolism and disposition in forced swimming test (FST) in rats. Albino Wistar rats were separated into three groups. Each group had 5 rats. Control animals received vehicle (DMF:Saline, 1:3 v/v) while test group treated with vehicle or fluoxetine $(20 \mathrm{mg} / \mathrm{kg})$ (i.p) $3.5 \mathrm{hr}$ prior to FST . Present study shows that holo, total enzyme activity was inhibited when rats subjected to FST and serum total TRP concentration was decreased while liver, brain TRP, 5-HT and 5-HIAA levels were increased in vehicle treated FST rats. Pretreatment with fluoxetine did not reduce immobility however it inhibited holo, total and apo enzyme activity. Pretreatment of fluoxetine also decreased serum total TRP and brain 5HT concentration while increased liver TRP, brain TRP, and 5-HIAA in FST rats when compared with their respective controls. Acute treatment with fluoxetine did not reduced immobility but it decrease brain 5-HT concentration by converting into 5-HIAA in FST rats which shows anxiolytic effect of fluoxetine.

Key words: Forced swimming Test, Fluoxetine, Tryptophan, 5-hydroxy tryptamine, 5-hydroxy indole acetic acid, anxiolytic.

Copyright @ 2019: This is an open-access article distributed under the terms of the Creative Commons Attribution license which permits unrestricted use, distribution, and reproduction in any medium for non-commercial use (NonCommercial, or CC-BY-NC) provided the original author and source are credited.

\section{INTRODUCTION}

Stress was initially defined by Hans Selye in 1936; He states that it is a condition which disturbs the physiological and psychological homeostasis mechanism of an organism [1]. Moreover chronic stress could be responsible to the progression of mental disorders. He proposed that the main factor which control stress response is hypothalamic-pituitaryadrenal (HPA) axis. Chronic stress can lead over secretion of glucocorticoids, increased concentration of cortisol and corticosterone can damage the hippocampal neurons. Depression is psychiatric disorders which affect $20 \%$ of an adult people overall the world. There are many factors which involve in pathophysiology of depression one of them is dysfunction of monoaminergic system.
This system is responsible for the behavioral and visceral characteristic of mood disorders [2]. The biogenic amine theory of depression illustrate that the low amount of brain 5 hydroxy tryptamine $(5-\mathrm{HT})$ and noradrenaline or catecholamine lead to depressive symptoms[3-4].One of the essential factors in etiology of mental disorders like depression and schizophrenia is disturbance of serotonergic system[5].

To evaluate the mode of action of antidepressant and etiology, the serotonin, neurotransmitter system is extensively investigated. Long term administration of different class of antidepressant (AD) could improve the serotonergic function and proof the involvement of serotonin in depression [6]. Serotonergic activity is improved by ADs drugs. The deficiency of serotonergic system 
might be possible due to: substrate unavailability, reduced tryptophan hydroxylase activity, any abnormalities in 5-HT up take or release, defect in 5HT receptor or contact with other neurotransmitters. Any changes of tryptophan (TRP) metabolism are a sign of clinical depression caused by immunological challenges [7] but stress also alter TRP metabolism.

Among all $\mathrm{AD}$ selective serotonin reuptake inhibitors (SSRIs) are commonly prescribed AD for last era whereas earliest groups of most widely used AD were tricyclic antidepressant (TCA) and (mono amine oxidase inhibitor) MAO [8]. Fluoxetine, a type of SSRI, is supposed to be more effective anxiolytic drug as compared with other SSRIs [9, 10]. Several researches show that fluoxetine is effective against mood disorders like depression, panic and anxiety [11, 12]. Acute fluoxetine treatment enhances synthesis of serotonin in brain[13]. The increase in the rate of synthesis of serotonin after fluoxetine administration is secondary to its primary inhibitory action of liver tryptophan 2,3dioxygenase (TDO) enzyme [14], which also enhances plasma free TRP concentration in animal. Chronic AD treatment has been found to diminish the sensitivity of corticotrophin releasing factor in neurons rather than their basal activity due to stress[15], which may contribute to normalization of HPA activity in patients undergoing psychopharmacological treatment. Earlier it was reported that chronic treatment with fluoxetine shows behavior anxiolytic effects devoid of reducing neuroendocrine responses to conditioned stress in rats[16]. Currently it was investigated that chronic treatment with imipramine reverse depressive-anxietylike behaviors by maintaining adrenocorticotropic hormone, and reducing interleukin- $1 \beta$ in the brain of rats when subjected to experimental periaical lesion[17].

Force swimming test (FST) is an animal model of depression. The FST is used to check AD action, drugs administered between pretest and test session reduce the interval of behavioral immobility. There is a link between dysfunction in monoamine transmission (5-HT, or nor-epinephrine NE) and depression [18]. Aim of current research is to find out the effects of fluoxetine administration on tryptophan metabolism and disposition in forced swimming rats.

\section{MATERIALS AND METHODS}

\section{Animal and treatment}

All protocols were strictly accompanied agreement with the national research council of laboratory animals. Ethical permission was taken from institutional animal Ethics committee, University of Karachi, Pakistan. Animals subjected to any treatment or procedures were made painless or minimize pain. Locally bred fifteen male Albino Wistar rats (150-200 gm body weight) were separated into three groups in plastic cage. Each group had five rats. They were kept at room temperature provide water and food for adjustment of animal to their environment before any treatment of experiment. Control group treated with saline $(0.95 \% \mathrm{NaCl})(2 \mathrm{ml} / \mathrm{kg})$ injected intraperitoneally (I.P) according to body weight. Test group also treated with saline followed subjected to forced swimming test. Drug treated test group injected fluoxetine $\mathrm{HCl}$ (20 $\mathrm{mg} / \mathrm{kg}$ ) (I.P) dissolved in vehicle (DMF: Saline) (1:3 $\mathrm{v} / \mathrm{v})$ after $3.5 \mathrm{hr}$ subjected to FST. All animals were killed after specific treatment and time by decapitation using guillotine. Whole sample (serum, brain and perfused liver) were kept immediately at $-70{ }^{\circ} \mathrm{C}$ till investigation.

\section{Biochemical Determinations}

TDO enzyme activity was estimated in rat liver homogenate. We took $2 \mathrm{gm}$ of frozen liver tissue homogenized in $13 \mathrm{ml}$ of $0.14 \mathrm{M} \mathrm{KCl}\left(\mathrm{pH} \mathrm{7.0)}\right.$ at $0^{\circ} \mathrm{C}$ using polytron homogenizer spinning at $13000 \mathrm{rpm}$ for 2-3 minutes either in the presence (total enzyme activity) of added haematin $2 \mu \mathrm{M}$ (haematin dissolved in $0.1 \mathrm{M} \mathrm{NaOH}$ ) or in absence (holo enzyme activity) as mention in detail[14]. The apo enzyme activity was estimated as the difference between total and holo enzyme activities. Serum total TRP, Brain TRP, 5-HT and 5-HIAA were measured by spectrofluorimetric procedures [19].

\section{Drug preparation}

Fluoxetine (Merck) was dissolved in DMF:Saline (1:3 v/v) and administered I.P at a dose of $20 \mathrm{mg} / \mathrm{kg}$ according to the body weight of rats and control groups treated with saline $(0.95 \% \mathrm{NaCl})$.

\section{Forced Swimming Test (FST)}

For behavioral study, animals were exposed to FST to make a model of depression. We put the animal in glass tank which height was $46 \mathrm{~cm}$ long and width was $20 \mathrm{~cm}$, tank was filled with water, the depth of water was $30 \mathrm{~cm}$ and temperature was $25 \pm 2^{\circ} \mathrm{C}$. The depth of water allowed the rats to easily swam and float in the tank without touching the bottom of tank. All test group rats were placed separately in tank for 15 minutes pretest, after 15 minutes rats were removed from water dried with towel and returned back to their cage. Twenty four hour later rats were treated with saline/drug, 3.5 hour after injection rats were again exposed to FST for 5-minutes. Control animals (untreated) were not exposed to force swimming test [20-21].

\section{Behavioral analysis}

Behavior was noted during the test swimming session using time-sampling method [9], one of three behaviors (climbing, swimming, immobility) was recorded at every five second. When animal was showing lowest movement required to stay afloat scored as immobility. When the animal was showing 
actively swimming and greater movement required to stay afloat in tank scored as swimming and when the animals was showing vigorous thrashing movements with its forepaws scored as climbing.

\section{RESULTS}

\section{Effects of FST and acute fluoxetine-HCl administration on TDO activity in rats}

Table.1 shows the effects of FST and acute fluoxetine on hepatic TDO activity in rats. Data analyzed by student t-test shows holo and total enzyme activities significantly inhibited, $(30.8 \% ; \mathrm{P}<0.001)$ and $(20.4 \%$; $\mathrm{P}<0.001)$ respectively in saline injected force swim rats when compared with untreated rats. While total and apo enzyme activities were inhibited (18.7\%; $\mathrm{P}<0.001 .33 .3 \% ; \mathrm{P}<0.01)$ in fluoxetine pretreated force swim rats, when compared with saline injected FST rats. Holo enzyme activity was inhibited by $31.7 \%$ $(\mathrm{P}<0.001), \quad(35.4 \% ; \mathrm{P}<0.001)$ and $(40 \% ; \mathrm{P}<0.001)$ respectively in fluoxetine treated force swim rats when compared with untreated control rats.

\section{Effects of FST and acute fluoxetine on serum total and liver TRP concentration in rats}

Table. 2 shows the effects of FST on serum total and liver TRP concentration in fluoxetinepretreated rats. Data analyzed by student t-test show that serum total TRP concentration was significantly decreased by $52.5 \%(\mathrm{P}<0.01)$ in saline injected FST rats when compared with $(16.8 \% ; \mathrm{P}<0.05)$ in fluoxetine pretreated FST rats when compared with untreated control rats. Serum TRP concentration was decreased $(60.5 \% \mathrm{P}<0.001)$ in fluoxetine treated FST rats when

\section{Statistical analysis}

Data was analyzed by student's t-test (SPSS version 15.00). All values are mean \pm SEM. $P<0.05$ considered as statistical significant.

compared with saline injected control rats. Hepatic TRP concentrations were significantly increased (50.3\%; $\mathrm{P}<0.001)$ in saline injected FST rats when compared with untreated control rats and $(70.5 \%$; $\mathrm{P}<0.001)$ in fluoxetine treated FST rats when compared with untreated control rats.

\section{Effects of FST and acute fluoxetine - $\mathrm{HCl}$ administration on brain indole concentration in rats} Table. 3 shows effects of FST on brain indoles in fluoxetine-pretreated rats. Data analyzed by student t-test show that brain TRP, and 5-HIAA concentration were significantly increased by $58.3 \% \quad(\mathrm{P}<0.001)$, $66.6 \%(\mathrm{P}<0.001)$, and $80 \%(\mathrm{P}<0.001)$, in saline injected FST rats when compared with untreated control rats. While, brain 5-HT concentration was decreased $(14 \% ; \quad \mathrm{P}<0.05)$ and 5-HIAA concentrations was increased $(33.3 \% ; \mathrm{P}<0.001)$ in fluoxetine-pretreated FST rats when compared with saline treated FST rats. Brain TRP, 5-HT and 5-HIAA concentrations were increased $(67.5 \% ; \mathrm{P}<0.001)(43.3 \% ; \mathrm{P}<0.001)$ and $(140$ $\% ; \mathrm{P}<0.001)$ respectively in fluoxetine-pretreated rats when compared with untreated control rats.

\section{Effects of acute fluoxetine-HCl on forced swimming test}

Table.4 shows that acute fluoxetine- $\mathrm{HCl}$ did not produce any significant effect on immobility.

Table-1: Effects of Forced Swimming Test and acute Fluoxetine-HCl (20mg/kg) (I.P) on hepatic tryptophan 2,3-dioxygenase (TDO) activity in rats

\begin{tabular}{|l|l|l|l|}
\hline Parameter & \multicolumn{4}{|l|}{ Tryptophan 2,3-dioxegenase activity ( $\boldsymbol{\mu M}$ of Kynurenine formed /h/g wet.wt.of liver) } \\
\hline & Untreated control & Saline+ forced swim & Fluoxetine+forced swim \\
\hline Holo enzyme & $2.17 \pm 0.1$ & $1.5 \pm 0.08 \dagger$ & $1.48 \pm 0.05 \delta$ \\
& & $-30.8 \%$ & $-31.7 \%$ \\
\hline Total enzyme & $4.15 \pm 0.06$ & $3.3 \pm 0.09 \dagger$ & $2.68 \pm 0.17 * \delta$ \\
& & $-20.4 \%$ & $-18.7 \%$ \\
& & & $-35.4 \%$ \\
\hline Apo enzyme & $2.0 \pm 0.07$ & $1.8 \pm 0.13$ & $1.2 \pm 0.12 * \delta$ \\
& & & $-33.3 \%$ \\
& & & $-40 \%$ \\
\hline
\end{tabular}

Experimental details are given in method's section. All values are mean \pm SEM for each group ( $n=5)$ animals. Statistical analysis performed using student t-test. Saline treated FST group when compared with untreated control is indicated by $\uparrow \mathrm{P}<0$.001. Fluoxetine- $\mathrm{HCl}$ treated FST group when compared with saline treated control is indicated by $* \mathrm{P}<0.01$ and when compared with untreated control is indicated by $\delta \mathrm{P}<0.001$.

Table-2: Effects of forced swimming test and acute Fluoxetine $(20 \mathrm{mg} / \mathrm{kg})$ on serum total and liver TRP concentrations in rats

\begin{tabular}{|l|l|l|l|}
\hline Parameter & Untreated control & Saline+ Forced swim & Fluoxetine + Forced swim \\
\hline Serum Total TRP & $15.11 \pm 1.65$ & $7.17 \pm 0.3 \dagger$ & $5.96 \pm 0.5 * \delta$ \\
$\boldsymbol{\mu g} / \mathbf{m l}$ & & $-52.5 \%$ & $-16.8 \%$ \\
& & & $-60.5 \%$ \\
\hline $\mathbf{L i v e r}$ TRP & $7.8 \pm 0.3$ & $11.73 \pm 0.37 \dagger \dagger$ & $13.3 \pm 1.07 \delta$ \\
$\boldsymbol{\mu g} / \mathbf{g}$ & & $50.3 \%$ & $-70.5 \%$ \\
\hline
\end{tabular}


Experimental details are given in method's section. All values are mean \pm SEM for each group $(n=5)$ animals. Statistical analysis performed using student t-test. Saline treated FST group when compared with untreated control is indicated by $\dagger \mathrm{P}<0.01$, $\dagger \dagger \mathrm{P}<0.001$. Fluoxetine- $\mathrm{HCl}$ treated FST group when compared with saline treated control is indicated by $* \mathrm{P}<0.05$ and when compared with untreated control is indicated by $\delta \mathrm{P}<0.001$.

Table-3: Effects of forced swimming test and acute fluoxetine $(20 \mathrm{mg} / \mathrm{kg})$ on serum total and liver TRP concentrations in rats

\begin{tabular}{|l|l|l|l|}
\hline Parameter & Untreated control & Saline+ Forced swim & Fluoxetine + Forced swim \\
\hline Brain TRP & $1.2 \pm 0.07$ & $1.9 \pm 0.07 \dagger$ & $2.01 \pm 0.04 \delta \delta$ \\
$\boldsymbol{\mu g} / \mathbf{g}$ & & $58.3 \%$ & $67.5 \%$ \\
\hline Brain 5-HT & $0.6 \pm 0.04$ & $1.0 \pm 0.05 \dagger$ & $0.86 \pm 0.05^{*} \delta$ \\
$\boldsymbol{\mu g} / \mathbf{g}$ & $66.6 \%$ & $43.3 \%$ \\
& & & $-14 \%$ \\
\hline Brain 5-HIAA & $0.25 \pm 0.05$ & $0.45 \pm 0.04 \dagger$ & $0.6 \pm 0.04^{* *} \delta \delta$ \\
$\boldsymbol{\mu g} / \mathbf{g}$ & & $80 \%$ & $140 \%$ \\
& & & $33.3 \%$ \\
\hline
\end{tabular}

Experimental details are given in method's section. All values are mean \pm SEM for each group ( $n=5)$ animals. Statistical analysis performed using student t-test. Saline treated FST group when compared with untreated control is indicated by $\dagger \mathrm{P}<0.001$. Fluoxetine-HCl treated FST group when compared with saline treated control is indicated by ${ }^{*} \mathrm{P}<0.05,{ }^{*} \mathrm{P}<0.001$ and when compared with untreated control is indicated by $\delta \mathrm{P}<0.01, \delta \delta \mathrm{P}<0.001$.

Table-4: Effects of acute administration of fluoxetine $(20 \mathrm{mg} / \mathrm{kg})$ on immobility in FST rats

\begin{tabular}{|l|l|l|}
\hline Parameter & FST & Fluoxetine + FST \\
\hline Immobility time (S) & $242 \pm 0.09$ & $238 \pm 0.07$ \\
\hline
\end{tabular}

Experimental details are given in material and method's section. Rats subjected to FST received an acute administration of Fluoxetine $(20 \mathrm{mg} / \mathrm{kg})$ and control rats received an equal volume of saline. All values are mean \pm SEM of five rats.

\section{DISCUSSION}

Currently SSRI commonly used AD and produce their $\mathrm{AD}$ response by enhancing synaptic concentration of serotonin. The FST is the most extensively used animal test for monitoring action of AD. The aim of the current study is to examine that whether acute administration of pretreated fluoxetine in FST rats produces anxiolytic effect.

The result shows that single administration of fluoxetine is given I.P at a dose of $20 \mathrm{mg} / \mathrm{kg}$, do not reduce the immobility time or depressive behavior of rats subjected to FST may be chronic treatment would produce any significant effect on behavioral activity. These results are similar with the other findings, which demonstrate that SSRI are lacking of any activity in this test in rats, whereas in mice they reduce the immobility time [22-24]. The mechanism of action of acutely administered SSRI leading to increased cerebral 5-HT synthesis by inhibiting the activity of liver TDO enzyme. In the same way we also found decreased holo, total enzyme activity, serum total TRP concentration and increases liver TRP concentration followed subjected to FST. The increase level of TRP in liver, provide increase availability for 5-HT synthesis. So, in the present study we also found increased brain TRP, serotonin and 5-HIAA levels in FST rats as compared to the saline treated control however fluoxetine treatment did not reverse the depressive symptoms but it decreases the 5-HT level in brain by converting into 5-HIAA. Pretreatment with fluoxetine also elevate brain TRP level in FST rats which shows fluoxetine inhibit the TDO enzyme activity. In contrast kreiss and Lucki [25] (1995) have also found transiently elevated levels of 5-HT in the striatum as compared to hippocampus. Similarly Kirby and Lucki [26] have also found acute administration of fluoxetine $(15 \mathrm{mg} / \mathrm{kg})$ slightly decreased lateral septum 5-HT; chronic treatments with SSRI are commonly used for several anxiety disorders; at the start of the treatment showed anxiety in patients. Similarly anxiety associated behaviors have seen in animal studies after a single injection with SSRIs. Fluoxetine $(20 \mathrm{mg} / \mathrm{kg})$ totally blocked exploration area induced anxiogenic effects in mice [27]. Repeated injection of fluoxetine $(1.0 \mathrm{mg} / \mathrm{kg}$ and $5.0 \mathrm{mg} / \mathrm{kg})$ has also produced anxiolytic effect in chronic mild stress rats [28].

\section{CONCLUSION}

In conclusion, our results showed depressive likes behaviors following exposure to FST. Moreover we also found increased level of neurotransmitter serotonin (5-HT) due to inhibition of TDO enzyme activity. Acute treatment with fluoxetine did not reduced immobility but it reduce brain 5-HT concentration by converting into 5-HIAA in FST rats which shows anxiolytic effect of fluoxetine. However more investigations needs to explain the chronic 
treatment of fluoxetine in FST rats and level of other neurotransmitter like catecholamine should be monitored.

\section{REFERENCES}

1. Farhan, M., \& Haleem, D. J. (2016). Anxiolytic profile of fluoxetine as monitored following repeated administration in animal rat model of chronic mild stress. Saudi Pharmaceutical Journal, 24(5), 571-578.

2. Nestler, E. J., Barrot, M., DiLeone, R. J., Eisch, A. J., Gold, S. J., \& Monteggia, L. M. (2002). Neurobiology of depression. Neuron, 34(1), 13-25.

3. Van Praag, H. M. (1978). Amine hypotheses of affective disorders. In Handbook of psychopharmacology (pp. 187-297). Springer, Boston, MA.

4. Wong, M. L., \& Licinio, J. (2001). Research and treatment approaches to depression. Nature Reviews Neuroscience, 2(5), 343.

5. Maes, M., \& Meltzer, H. Y. (1995). The serotonin hypothesis of major depression. E. BF, DJ K, editors.

6. Blier, P., \& Chaput, Y. (1988). Electrophysiological assessment of the effects of antidepressant treatments on the efficacy of 5-HT neurotransmission. Clinical

neuropharmacology, 11, S1-10.

7. Wichers, M. C., Koek, G. H., Robaeys, G., Verkerk, R., Scharpe, S., \& Maes, M. J. M. P. (2005). IDO and interferon- $\alpha$-induced depressive symptoms: a shift in hypothesis from tryptophan depletion to neurotoxicity. Molecular psychiatry, 10(6), 538.

8. Artigas, F., Nutt, D. J., \& Shelton, R. (2002). Mechanism of action of antidepressants. Psychopharmacology bulletin, 36, 123-132.

9. Detke, M. J., Rickels, M., \& Lucki, I. (1995). Active behaviors in the rat forced swimming test differentially produced by serotonergic and noradrenergic antidepressants. Psychopharmacology, 121(1), 6672.

10. Contreras, C. M., Rodríguez-Landa, J. F., Gutiérrez-García, A. G., \& Bernal-Morales, B. (2001). The lowest effective dose of fluoxetine in the forced swim test significantly affects the firing rate of lateral septal nucleus neurones in the rat. Journal of Psychopharmacology, 15(4), 231236.

11. Kindler, S., Dolberg, O. T., Cohen, H., Hirschmann, S., \& Kotler, M. (1997). The treatment of comorbid premature ejaculation and panic disorder with fluoxetine. Clinical neuropharmacology, 20(5), 466-471.

\section{ACKNOWLEDGMENT}

We thank Higher education commission, Islamabad Pakistan for the financial support.

12. Mancini, C., \& Ameringen, M. V. (1996). Paroxetine in social phobia. The Journal of clinical psychiatry, 57(11), 519-522.

13. Tsuiki, K., Yamamoto, Y. L., \& Diksic, M. (1995). Effect of acute fluoxetine treatment on the brain serotonin synthesis as measured by the $\alpha$-methyl-Ltryptophan autoradiographic method. Journal of neurochemistry, 65(1), 250-256.

14. Bano, S., \& Sherkheli, M. A. (2003). Inhibition of tryptophan-pyrrolase activity and elevation of brain tryptophan concentration by fluoxetine in rats. Journal of the College of Physicians and Surgeons--Pakistan: JCPSP, 13(1), 5-10.

15. Stout, S. C., Owens, M. J., \& Nemeroff, C. B. (2002). Regulation of corticotropin-releasing factor neuronal systems and hypothalamic-pituitaryadrenal axis activity by stress and chronic antidepressant treatment. Journal of Pharmacology and Experimental Therapeutics,300(3), 10851092.

16. Zhang, Y., Raap, D. K., Garcia, F., Serres, F., Ma, Q., Battaglia, G., \& Van de Kar, L. D. (2000). Long-term fluoxetine produces behavioral anxiolytic effects without inhibiting neuroendocrine responses to conditioned stress in rats. Brain research, 855(1), 58-66.

17. Simões, L. R., Netto, S., Generoso, J. S., Ceretta, R. A., Valim, R. F., Dominguini, D., \& Barichello, T. (2019). Imipramine treatment reverses depressive-and anxiety-like behaviors, normalize adrenocorticotropic hormone, and reduce interleukin-1 $\beta$ in the brain of rats subjected to experimental periapical lesion. Pharmacological Reports, 71(1), 24-31.

18. Delgado, P. L., Price, L. H., Miller, H. L., Salomon, R. M., Aghajanian, G. K., Heninger, G. R., \& Charney, D. S. (1994). Serotonin and the neurobiology of depression: effects of tryptophan depletion in drug-free depressed patients. Archives of General Psychiatry, 51(11), 865-874.

19. BANO, S., ORETTI, R. G., Morgan, C. J., Badawy, A. A. B., Buckland, P. R., \& Mcguffin, P. (1996). Effects of chronic administration and subsequent withdrawal of ethanol-containing liquid diet on rat liver tryptophan pyrrolase and tryptophan metabolism. Alcohol and Alcoholism, 31(2), 205-215.

20. Porsolt, R. D., Anton, G., Blavet, N., \& Jalfre, M. (1978). Behavioural despair in rats: a new model sensitive to antidepressant treatments. European journal of pharmacology, 47(4), 379-391.

21. Lucki, I., Dalvi, A., \& Mayorga, A. J. (2001). Sensitivity to the effects of pharmacologically selective antidepressants in different strains of mice. Psychopharmacology, 155(3), 315-322. 
22. Borsini, F. (1995). Role of the serotonergic system in the forced swimming test. Neuroscience \& Biobehavioral Reviews, 19(3), 377-395.

23. Borsini, F., \& Meli, A. (1988). Is the forced swimming test a suitable model for revealing antidepressant activity?. Psychopharmacology, 94(2), 147-160.

24. Tatarczyñska, E., Klodzinska, A., \& ChojnackaWójcik, E. (2002). Effects of combined administration of 5-HT 1 A and/or 5-HT 1 B receptor antagonists and paroxetine or fluoxetine in the forced swimming test in rats. Polish journal of pharmacology, 54(6), 615-624.

25. Kreiss, D. S., \& Lucki, I. (1995). Effects of acute and repeated administration of antidepressant drugs on extracellular levels of 5-hydroxytryptamine measured in vivo. Journal of Pharmacology and Experimental Therapeutics, 274(2), 866-876.
26. Kirby, L. G., \& Lucki, I. (1997). Interaction between the forced swimming test and fluoxetine treatment on extracellular 5-hydroxytryptamine and 5-hydroxyindoleacetic acid in the rat. Journal of Pharmacology and Experimental Therapeutics, 282(2), 967-976.

27. Belzung, C., Le Guisquet, A. M., Barreau, S., \& Calatayud, F. (2001). An investigation of the mechanisms responsible for acute fluoxetineinduced anxiogenic-like effects in mice. Behavioural pharmacology, 12(3), 151-162.

28. Farhan, M., \& Haleem, D. J. (2016). Anxiolytic profile of fluoxetine as monitored following repeated administration in animal rat model of chronic mild stress. Saudi Pharmaceutical Journal, 24(5), 571-578. 